\title{
Free ammonia pretreatment for anaerobic sludge digestion reduces the spread of antibiotic resistance
}

\author{
Zehao Zhang, Huan Liu, Qilin Wang*
}

Centre for Technology in Water and Wastewater, School of Civil and Environmental Engineering, University of Technology Sydney, Ultimo, NSW 2007, Australia

${ }^{*}$ Corresponding author.

E-mail: Qilin.Wang@uts.edu.au (Q. Wang)

\begin{abstract}
Sludge from the wastewater treatment plants (WWTPs) has been recognized as a reservoir of antibiotic resistance genes (ARGs). Free ammonia (FA, i.e. $\left.\mathrm{NH}_{3}-\mathrm{N}\right)$ pretreatment has been demonstrated to be able to enhance anaerobic digestion, which is a widely used method for sludge treatment. However, the effect of combined FA pretreatment and anaerobic digestion on the fate of ARGs is still unknown. This study demonstrated for the first time that combined FA pretreatment (420 $\mathrm{mg} \mathrm{NH}_{3}-\mathrm{N} / \mathrm{L}$ for $24 \mathrm{~h}$ ) and anaerobic digestion could reduce the abundances of the tested ARGs by $0.06 \log _{10}$ gene copies/g TS (total solids) compared with the anaerobic digestion alone. Specifically, the experimental results showed that combined FA pretreatment and anaerobic digestion reduced the abundances of $a a c\left(6^{\prime}\right)-I b-c r$, blaTEM, sul2, tetA, tetB and tet $X$ by $0.07,0.37,0.09,0.32,0.24$ and $0.59 \log _{10}$ gene copies/g TS compared with anaerobic digestion alone. In contrast, combined FA pretreatment and anaerobic digestion slightly increased the abundance of tet $G$ by $0.05 \log _{10}$ gene copies/g TS compared with anaerobic digestion alone. In addition, FA pretreatment did not significantly affect the abundance of sull and tet $M$ during anaerobic digestion. This study revealed that FA pretreatment for anaerobic
\end{abstract}


digestion could potentially reduce the spread of antibiotic resistance from the sludge to soil (while agriculture reuse is used as the sludge disposal method), thereby protecting the environment and human health.

\section{Introduction}

Antibiotics have been produced and applied in medical care, poultry farming and aquaculture to promote human health and agricultural production for more than 70 years (Xue et al., 2019). However, antibiotic resistance caused by the intensive use of antibiotics poses a global threat to public well-being (Pei et al., 2016). For instance, the Center for Disease Control and Prevention reported the death of more than 35,000 people in America each year owing to antibiotic resistance.

Antibiotic resistance genes (ARGs) widely disseminate in bacterial communities through vertical gene transfer and horizontal gene transfer (Shao et al., 2018; Xue et al., 2019; Zhang et al., 2018). The VGT means antibiotic resistance bacteria (ARB) pass on ARGs through cell reproduction (Shao et al., 2018). The horizontal gene transfer means non-ARB obtain one or multiple ARGs from ARB or environments (Shao et al., 2018; Xue et al., 2019; Zhang et al., 2018).

Sludge in wastewater treatment plants (WWTPs) is recognized as a reservoir and environmental supplier for ARGs and ARB (Heuer et al., 2011; Karkman et al., 2018; Smets and Barkay, 2005; Zhu et al., 2013). The antibiotics from domestic households and hospitals enter into the WWTPs, which causes the occurrence of ARGs in various wastewater treatment bacteria (Aminov, 2011; Karkman et al., 2018). More than 99\% of these ARGs will then finally accumulate in sludge (Xue et al., 2019; Yang et al., 2014). For instance, tetracyclines (tet) are 
spectrum antibiotics, which are commonly used in humans, livestock, and aquaculture (Martınez et al., 2015; Wang et al., 2016). These antibiotics have caused the occurrence of significant amounts of tet resistance genes in sludge. It was reported that the abundance of tet $A$ and tetQ in sludge could reach $10^{8}-10^{9}$ copies/g-TS (total solids) and $10^{4}-10^{7}$ copies/g-TS, respectively (Auerbach et al., 2007). Agricultural reuse is a common sludge disposal method. For example, more than 67\% of sludge is reused in agriculture in Australia (Australian Water Association, 2020). This may lead to the spread of ARGs from sludge to the local environment, thereby increasing the risk of sludge reuse to human health.

Anaerobic digestion is a typical sludge treatment method because it achieves sludge reduction (Batstone et al., 2002). Recently, it is reported that anaerobic digestion can also affect the fate of some types of ARGs. For instance, Pei et al. (2016) found that anaerobic digestion could decrease the total abundance of tet $A$, tet $G$, tet $Q$, tet $Q$ and tet $X$ by up to $1.00 \log _{10}$ gene copies/g TS. Anaerobic digestion is often limited by the poor biodegradability of the sludge. Therefore, several pretreatment methods have been developed to enhance sludge biodegradability, thereby enhancing sludge reduction. For instance, it has been reported that free ammonia (FA, i.e., $\left.\mathrm{NH}_{3}\right)$ pretreatment at $420 \mathrm{mg} \mathrm{N} / \mathrm{L}$ for $24 \mathrm{~h}$ enhanced sludge biodegradability by $20 \%$ (Wei et al., 2017). The FA pretreatment technology relies on a renewable material (i.e. FA) from wastewater, making this technology quite promising.

Recently, it has been found that some pretreatment technologies affected the fate of ARGs. For instance, Pei et al. (2016) showed that the thermal hydrolysis pretreatment could enhance the reduction of five tet resistance genes by $0.5 \log$ copies/g-TS in anaerobic digestion. However, it is still unknown how the FA pretreatment technology will affect the fate of ARGs in anaerobic digestion. 
This study aimed to assess the effect of FA pretreatment on the spread of antibiotic resistance during anaerobic sludge digestion. Nine ARGs were selected to quantify in this study, which were $a a c\left(6^{\prime}\right)-I b-c r$, blaTEM, sull, sul2, tetA, tetB, tet $G$, tetM and tet $X$.

\section{Materials and methods}

\section{Secondary sludge and inoculum}

The secondary sludge was collected from the thickener of a wastewater treatment plant (WWTP) conducting biological nitrogen and phosphorus removal. The WWTP has a sludge retention time (SRT) of $12-16 \mathrm{~d}$. The inoculum was collected from a mesophilic anaerobic digester treating a mixture of primary and secondary sludges in the WWTP from which secondary sludge was collected. The mesophilic anaerobic digester has an SRT of $15-18 \mathrm{~d}$.

\section{Pretreatment of secondary sludge with FA}

Batch experiments were conducted to evaluate the impact of FA pretreatment on the abundances of detected ARGs. 1 L of secondary sludge was evenly distributed into two batch reactors. For FA pretreatment, a certain amount of ammonium stock solution (3.0 M) was added to one of the two batch reactors to obtain a total ammonia nitrogen $\left(\mathrm{NH}_{4}{ }^{+}-\mathrm{N}+\mathrm{NH}_{3}-\mathrm{N}\right)$ concentration of $500 \mathrm{mg} \mathrm{N} / \mathrm{L}$. pH was adjusted and maintained at $10.0 \pm 0.1$ using $\mathrm{NaOH}$ solution. The pretreatment was conducted in a temperature-controlled room $\left(25^{\circ} \mathrm{C}\right)$ and lasted for $24 \mathrm{~h}$. The total ammonia nitrogen, $\mathrm{pH}$ and the temperature collectively resulted in an FA concentration of $420 \mathrm{mg} \mathrm{NH}-\mathrm{N} / \mathrm{L}$, which was determined by the formula $\mathrm{S}_{(\mathrm{NH} 4-\mathrm{N}+\mathrm{NH} 3-\mathrm{N})} \times$ $10^{\mathrm{pH}} /\left(\mathrm{K}_{\mathrm{b}} / \mathrm{K}_{\mathrm{w}}+10^{\mathrm{pH}}\right)$. The $\mathrm{S}_{(\mathrm{NH} 4-\mathrm{N}+\mathrm{NH} 3-\mathrm{N})}$ is the total ammonia nitrogen concentration. The $\mathrm{K}_{\mathrm{b}} / \mathrm{K}_{\mathrm{W}}$ is equal to $\mathrm{e}^{6,344 /(273+\mathrm{T})}$ (Anthonisen et al., 1976). This ammonia concentration (i.e. $420 \mathrm{mg} \mathrm{NH} \mathrm{N}^{-}$ N/L) was selected based on our previous tests (Wei et al., 2017), which demonstrated that FA pretreatment at $420 \mathrm{mg} \mathrm{NH}_{3}-\mathrm{N} / \mathrm{L}$ for $24 \mathrm{~h}$ led to the highest methane production with a large 
economic advantage. The other batch reactor was also set up without ammonium addition or $\mathrm{pH}$ control. This reactor served as a control. The sludge samples were taken both before and after pretreatment for the determination ARGs using real-time quantitative PCR (RT-qPCR) to be described below.

\section{Anaerobic digestion tests}

Anaerobic digestion tests were performed to evaluate the effect of combined FA pretreatment with anaerobic digestion on the abundances of detected ARGs. The serum vials (160 mL) with a working volume of $100 \mathrm{~mL}$ were used to carry out the anaerobic digestion tests. Both the inoculum and the secondary sludge were added into every serum vial, resulting in a VS based inoculum to sludge ratio of approximately 2.0. The vials were flushed with helium gas for 2 $\min (1 \mathrm{~L} / \mathrm{min})$ to ensure an anaerobic condition. After that, a rubber stopper with an aluminum crimp cap was used to seal the vials, which were then put in an incubator operated at $37{ }^{\circ} \mathrm{C}$. Triplicate tests were conducted. The anaerobic digestion tests lasted for 45 days. The digested sludges with and without FA pretreatment were sampled for the analysis of ARGs by $R T-q P C R$.

\section{$D N A$ extraction and $R T-q P C R$}

$0.25 \mathrm{~g}$ of sludge of each sample was used for DNA extraction using the Fast DNA Spin Kit for Soil (MP Biomedicals, USA). 1\% agarose gel electrophoresis and NanoDrop ND-1000 (NanoDrop, USA) were used to determine the quality and concentration of the extracted DNA. Triplicate extracts were conducted to get a representative DNA sample.

RT-qPCR was used for the quantification of ARGs. One aminoglycoside and fluoroquinolone resistance gene (i.e. $\left.a a c\left(6^{\prime}\right)-I b-c r\right)$, one beta-lactamase resistance gene (i.e. blaTEM), two sulfonamide resistance genes (i.e. sull and sul2) and five tet resistance genes (i.e. tetA, tetB, 
tet $G$, tet $M$ and tet $X$ ) were selected in this study. PCR was conducted based on the method in Zhang et al. (2017). The primers and standard PCR conditions employed are described in the Supporting Information (Table S1). The abundances of ARGs were expressed as the gene copies divided by the TS of the sludge (i.e., gene copies per gram TS).

\section{Results}

Effects of FA pretreatment on the fate of ARGs

The effect of FA pretreatment on the fate of ARGs in sludge is shown in Fig. 1 and Table 1, which show FA pretreatment significantly affected the abundance of ARGs. FA pretreatment at $420 \mathrm{mg} \mathrm{N} / \mathrm{L}$ for $24 \mathrm{~h}$ decreased the abundances of blaTEM, sull, sul2, tetA, tetB and tet $X$ by $0.10,0.04,0.58,0.20$ and $0.61 \log _{10}$ copies/g-TS, respectively, which were from $7.76 \times 10^{6}$, $1.64 \times 10^{9}, 6.35 \times 10^{8}, 3.40 \times 10^{7}, 1.72 \times 10^{8}$ and $7.82 \times 10^{7}$ gene copies/g-TS to $6.17 \times 10^{6}, 1.51 \times 10^{9}$, $5.31 \times 10^{8}, 9.11 \times 10^{6}, 1.07 \times 10^{8}$ and $1.93 \times 10^{7}$ gene copies/g-TS, respectively. In contrast, FA pretreatment increased the abundance of tet $M$ by $0.71 \log _{10}$ copies/g-TS, which were from $4.09 \times 10^{6}$ gene copies/g-TS to $2.10 \times 10^{7}$ gene copies/g-TS. In terms of aac $\left(6^{\prime}\right)-I b-c r$ and $t e t G$, FA pretreatment did not significantly affect their abundances, which were maintained at around $3.30 \times 10^{9}$ and $9.00 \times 10^{7}$ gene copies/g-TS both before and after FA pretreatment. Overall, FA pretreatment at $420 \mathrm{mg} \mathrm{N} / \mathrm{L}$ for $24 \mathrm{~h}$ decreased the abundance of the tested ARGs by $0.04 \log _{10}$ copies/g-TS, which decreased from $6.01 \times 10^{9}$ gene copies/g-TS to $5.47 \times 10^{9}$ gene copies/g-TS. This demonstrated that FA pretreatment is effective in removing the tested ARGs.

\section{Effects of combined FA pretreatment and anaerobic digestion on the fate of ARGs}

The effect of combined FA pretreatment and anaerobic digestion on the fate of ARGs is shown in Fig. 1 and Table 2. Compared with the anaerobic digestion alone, combined FA pretreatment and anaerobic digestion could further reduce the abundances of aac $\left(6^{\prime}\right)-i b-c r$, blaTEM, sul2, 
tet $A$, tet $B$ and tet $X$ by $0.07,0.37,0.09,0.32,0.24$ and $0.59 \log _{10}$ copies/g-TS, respectively, which were from $2.62 \times 10^{9}, 2.05 \times 10^{7}, 3.40 \times 10^{8}, 3.65 \times 10^{6}, 9.45 \times 10^{7}$ and $1.48 \times 10^{7}$ gene copies/g-TS in the digested untreated sludge to $2.16 \times 10^{9}, 8.62 \times 10^{6}, 2.76 \times 10^{8} 1.90 \times 10^{6}$, $3.94 \times 10^{7}$ and $1.10 \times 10^{7}$ gene copies/g-TS in the digested FA-pretreated sludge, respectively. On the contrary, combined FA pretreatment and anaerobic digestion slightly increased the abundance of tet $G$ by $0.06 \log _{10}$ copies/g-TS compared with the anaerobic digestion alone, which was from $5.79 \times 10^{7}$ gene copies/g-TS in the digested untreated sludge to $6.59 \times 10^{7}$ gene copies/g-TS in the digested FA-pretreated sludge. In addition, combined FA pretreatment and anaerobic digestion did not affect the abundances of sull and tet $M$, which were maintained at approximately $1.04 \times 10^{9}$ and $2.80 \times 10^{7}$ gene copies/g-TS in both digested untreated sludge and digested FA-pretreated sludge. In total, combined FA pretreatment and anaerobic digestion reduced the abundance of the tested ARGs by $0.06 \log _{10}$ copies/g-TS compared with the anaerobic digestion alone, which was from $4.21 \times 10^{9}$ gene copies/g-TS in the digested untreated sludge to $3.64 \times 10^{9}$ gene copies/g-TS in the digested FA-pretreated sludge. Therefore, combined FA pretreatment and anaerobic digestion is effective in reducing the abundance of the tested ARGs. 


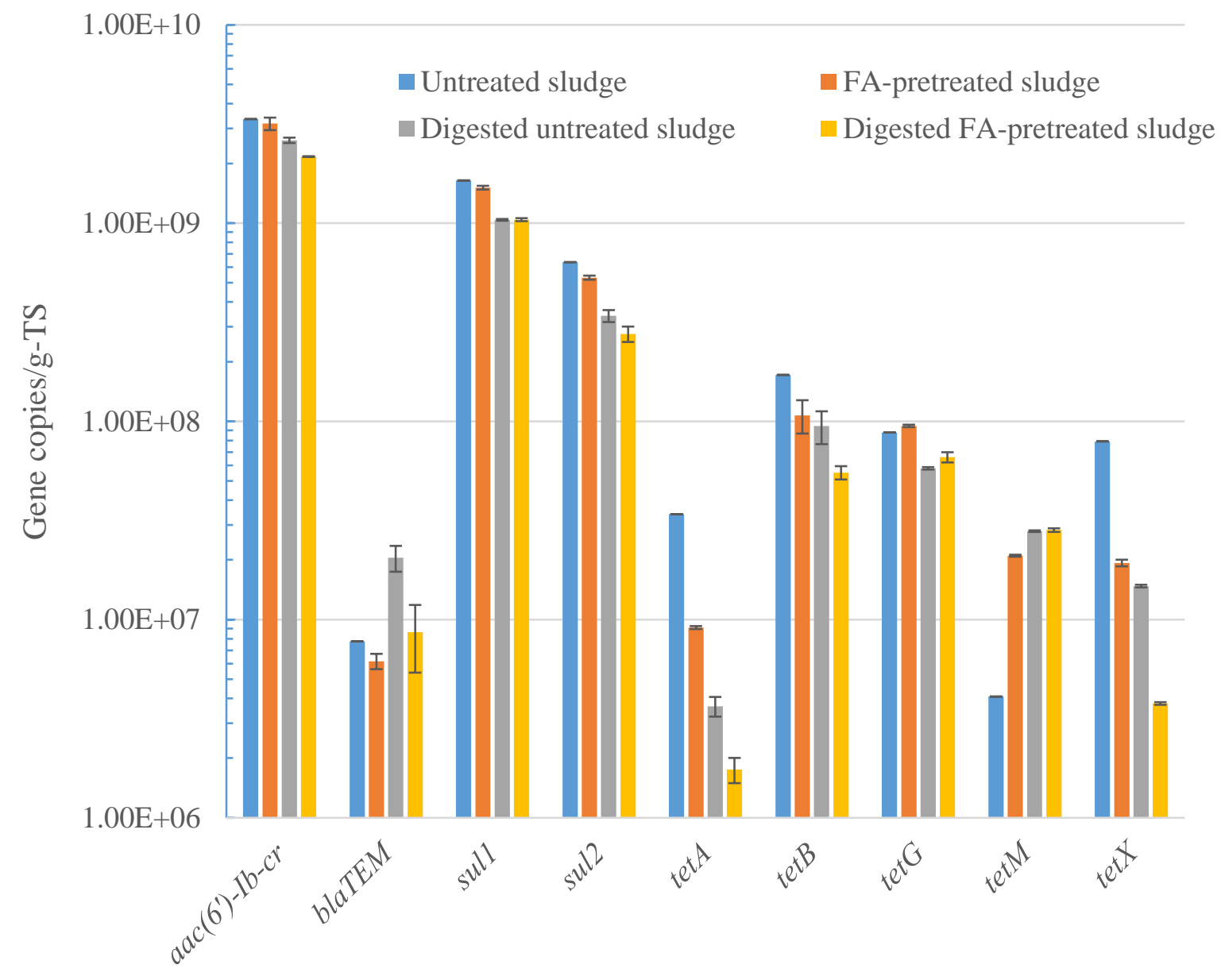

Figure 1. Abundances of ARGs in different sludges 
Table 1. Effects of FA pretreatment on the fate of ARGs

\begin{tabular}{|c|c|c|c|c|c|c|c|c|c|c|}
\hline & \multicolumn{10}{|c|}{ Abundances of the ARGs $\left(\log _{10}\right.$ gene copies/g-TS) } \\
\hline & $a a c\left(6^{\prime}\right)-i b-c r$ & blaTEM & sull & sul2 & tetA & tet $B$ & $\operatorname{tet} G$ & tetM & tet $X$ & ARGs \\
\hline Untreated sludge & 9.52 & 6.89 & 9.22 & 8.8 & 7.53 & 8.23 & 7.94 & 6.61 & 7.9 & 9.78 \\
\hline FA-pretreated sludge & 9.5 & 6.79 & 9.18 & 8.72 & 6.95 & 8.03 & 7.98 & 7.32 & 7.29 & 9.74 \\
\hline$\Delta$ Abundance & 0.02 & 0.1 & 0.04 & 0.08 & 0.58 & 0.2 & -0.04 & -0.71 & 0.61 & 0.04 \\
\hline
\end{tabular}

Note: The negative value means the target gene is increased.

Table 2. Effects of combined FA pretreatment and anaerobic digestion on the fate of ARGs

\begin{tabular}{|c|c|c|c|c|c|c|c|c|c|c|}
\hline & \multicolumn{10}{|c|}{ Abundances of the ARGs $\left(\log _{10}\right.$ gene copies/g-TS) } \\
\hline & $a a c\left(6^{\prime}\right)-i b-c r$ & blaTEM & sull & sul2 & tetA & tetB & tet $G$ & tetM & tet $X$ & ARGs \\
\hline $\begin{array}{l}\text { Digested untreated } \\
\text { sludge }\end{array}$ & 9.41 & 7.31 & 9.02 & 8.53 & 6.56 & 7.98 & 7.76 & 7.45 & 7.17 & 9.62 \\
\hline $\begin{array}{l}\text { Digested FA-pretreated } \\
\text { sludge }\end{array}$ & 9.34 & 6.94 & 9.02 & 8.44 & 6.24 & 7.74 & 7.81 & 7.45 & 6.58 & 9.56 \\
\hline$\Delta$ Abundance & 0.07 & 0.37 & 0.00 & 0.09 & 0.32 & 0.24 & -0.05 & 0.00 & 0.59 & 0.06 \\
\hline
\end{tabular}

Note: The negative value means the target gene is increased. 
bioRxiv preprint doi: https://doi.org/10.1101/2020.09.11.291054; this version posted September 12, 2020. The copyright holder for this preprint (which was not certified by peer review) is the author/funder, who has granted bioRxiv a license to display the preprint in perpetuity. It is made available under aCC-BY-NC-ND 4.0 International license.

\section{Conclusion}

Compared with anaerobic digestion alone, combined FA pretreatment and anaerobic digestion could reduce the abundances of antibiotic resistance genes. It reduced the abundances of aac(6')-ib-cr, blaTEM, sul2, tet $A$, tetB and tet $X$ by $0.07,0.37,0.09,0.32,0.24$ and $0.59 \log _{10}$ copies/g-TS compared with the anaerobic digestion alone, but slightly increased the abundance of $\operatorname{tet} G$ by $0.06 \log _{10}$ copies/g-TS with the anaerobic digestion alone. Combined FA pretreatment and anaerobic digestion did not significantly affect the abundances of sull and tet $M$ compared with the anaerobic digestion alone. FA pretreatment can be used as a potential method to reduce the spread of antibiotic resistance from sludge to the environment.

\section{References}

Aminov, R.I. 2011. Horizontal gene exchange in environmental microbiota. Frontiers in microbiology 2, 158.

Anthonisen, A.C., Loehr, R.C., Prakasam, T. and Srinath, E. 1976. Inhibition of nitrification by ammonia and nitrous acid. Journal (Water Pollution Control Federation), 835-852.

Auerbach, E.A., Seyfried, E.E. and McMahon, K.D. 2007. Tetracycline resistance genes in activated sludge wastewater treatment plants. Water research 41(5), 1143-1151.

Australia Water Association 2020, Australian Biosolids Statistics, $<$ https://www.biosolids. com.au/guidelines/australian-biosolids-statistics/ >.

Batstone, D.J., Keller, J., Angelidaki, I., Kalyuzhnyi, S., Pavlostathis, S., Rozzi, A., Sanders, W., Siegrist, H. and Vavilin, V. 2002. The IWA anaerobic digestion model no 1 (ADM1). Water Science and technology 45(10), 65-73.

Heuer, H., Schmitt, H. and Smalla, K. 2011. Antibiotic resistance gene spread due to manure application on agricultural fields. Current opinion in microbiology 14(3), 236-243.

Karkman, A., Do, T.T., Walsh, F. and Virta, M.P. 2018. Antibiotic-resistance genes in waste water. Trends in microbiology 26(3), 220-228.

Martınez, J., Coque, T. and Baquero, F. 2015. What is a resistance gene? Ranking risk in resistomes. Nat Rev Microbiol 13(2), 116-123.

Pei, J., Yao, H., Wang, H., Ren, J. and Yu, X. 2016. Comparison of ozone and thermal hydrolysis combined with anaerobic digestion for municipal and pharmaceutical waste sludge with tetracycline resistance genes. Water Res 99, 122-128.

Shao, S., Hu, Y., Cheng, J. and Chen, Y. 2018. Research progress on distribution, migration, transformation of antibiotics and antibiotic resistance genes (ARGs) in aquatic environment. Critical reviews in biotechnology 38(8), 1195-1208.

Smets, B.F. and Barkay, T. 2005 Horizontal gene transfer: perspectives at a crossroads of scientific disciplines, Nature Publishing Group.

Wang, D.N., Liu, L., Qiu, Z.G., Shen, Z.Q., Guo, X., Yang, D., Li, J., Liu, W.L., Jin, M. and Li, J.W. 2016. A new adsorption-elution technique for the concentration of aquatic extracellular antibiotic resistance genes from large volumes of water. Water Res 92, 
188-198.

Wei, W., Zhou, X., Wang, D., Sun, J. and Wang, Q. 2017. Free ammonia pre-treatment of secondary sludge significantly increases anaerobic methane production. Water research $118,12-19$.

Xue, G., Jiang, M., Chen, H., Sun, M., Liu, Y., Li, X. and Gao, P. 2019. Critical review of ARGs reduction behavior in various sludge and sewage treatment processes in wastewater treatment plants. Critical Reviews in Environmental Science and Technology 49(18), 1623-1674.

Yang, Y., Li, B., Zou, S., Fang, H.H. and Zhang, T. 2014. Fate of antibiotic resistance genes in sewage treatment plant revealed by metagenomic approach. Water Res 62, 97-106.

Zhang, J., Liu, J., Wang, Y., Yu, D., Sui, Q., Wang, R., Chen, M., Tong, J. and Wei, Y. 2017. Profiles and drivers of antibiotic resistance genes distribution in one-stage and twostage sludge anaerobic digestion based on microwave-H2O2 pretreatment. Bioresour Technol 241, 573-581.

Zhang, Q.-Q., Tian, G.-M. and Jin, R.-C. 2018. The occurrence, maintenance, and proliferation of antibiotic resistance genes (ARGs) in the environment: influencing factors, mechanisms, and elimination strategies. Applied microbiology and biotechnology 102(19), 8261-8274.

Zhu, Y.-G., Johnson, T.A., Su, J.-Q., Qiao, M., Guo, G.-X., Stedtfeld, R.D., Hashsham, S.A. and Tiedje, J.M. 2013. Diverse and abundant antibiotic resistance genes in Chinese swine farms. Proceedings of the National Academy of Sciences 110(9), 3435-3440. 